\title{
COMUNICAÇÃO
}

\section{VARIABILIDADE GENÉTICA DE ISOLADOS DO COGUMELO Agaricus blazei POR MEIO DE MARCADORES RAPD ${ }^{1}$}

\author{
Genetic variability of mushroom isolates Agaricus blazei using markers rapd \\ Márcia Mayumi Tomizawa², Eustáquio Souza Dias ${ }^{3}$, Leandro José de Assis ${ }^{4}$, \\ Plínio Henrique Oliveira Gomide ${ }^{5}$, João Bosco dos Santos ${ }^{6}$
}

\begin{abstract}
RESUMO
Agaricus blazei (Murrill) ss. Heinem. é um cogumelo nativo do Brasil que vem despertando a atenção de vários pesquisadores em todo o mundo, devido às suas propriedades farmacológicas e nutricionais. Este trabalho teve por objetivo, analisar a variabilidade genética de alguns isolados utilizados comercialmente, por meio de marcadores RAPD. Foram analisados nove isolados de A. blazei, provenientes de diferentes regiões do Brasil e, como controle, dois isolados de A. bisporus. Todos eles fazem parte da coleção de fungos do Laboratório de Cogumelos Comestíveis e Medicinais do DBI/UFLA. Diferentes primers aleatórios foram utilizados, gerando um total de 139 bandas polimórficas. Procedeu-se a avaliação de similaridade genética entre os isolados pelo coeficiente de Dice e análise de agrupamento pelo método UPGMA. Os resultados revelaram que dos 9 isolados de A. blazei, 6 (CS1, CS3, CS4, CS6, CS8 e CS9) apresentaram uma alta similaridade genética, sendo considerados isolados de uma mesma origem ou clones. O isolado CS2 foi o que apresentou a maior divergência genética em relação aos demais, seguido dos isolados CS5 e CS7, os quais formaram cada um, um grupo a parte, com médias de 60,6\%,88,7\% e 91,3\% de similaridade genética, respectivamente.
\end{abstract}

Termos para indexação: Variabilidade, RAPD, Cogumelo, Agaricus blazei.

\begin{abstract}
Agaricus blazei (Murrill) ss. Heinem. is a Brazilian native mushroom which has called the attention of several researchers all over the world due to its nutritional and pharmacological properties. The objective of this study was to evaluate the genetic variability of some isolates commercially used, using RAPD markers. Nine isolates of A. blazei were analyzed, from different regions in the country, and two isolates of the A. bisporus, which served as control group. All of them are part of the collection of mushroom of the Edible and Medicinal Mushroom Laboratory of DBI/UFLA. For RAPD analysis, different random primers were used, generating 139 polymorphic bands. The genetic similarity evaluation was proceeded between the isolates by means of Dice coefficient and grouping analysis through the UPGMA method. The results showed that from the 9 isolates of A. blazei, 6 (CS1, CS3, CS4, CS6, CS8 e CS9) have shown a high genetic similarity and these were considered isolates of the same origin or clones. The CS2 was the isolate which showed the higher genetic divergence in relation to the others, followed by the CS5 and CS7, with averages of $60.6 \%, 88.7 \%$ and $91.3 \%$ genetic similarity, respectively.
\end{abstract}

Index terms: Variability, RAPD, Mushroom, Agaricus blazei.

(Recebido em 29 de agosto de 2005 e aprovado em 31 de maio de 2006)

Agaricus blazei (Murrill) ss. Heinemann é um cogumelo nativo do Brasil que se tornou mundialmente conhecido devido às suas propriedades farmacológicas e nutricionais. No Brasil, a espécie ficou conhecida popularmente como "cogumelo do sol", pelo fato de crescer em campo aberto, sendo conhecido também como cogumelo piedade, cogumelo medicinal, cogumelo princesa, cogumelo-de-Deus, cogumelo da vida, cogumelo dos deuses (MIZUNO, 1995) e, mais recentemente, Champignon do Brasil (AMAZONAS, 2004). No Japão, ele é conhecido como himematsutake ou kawariharatake (MIZUNO, 1995) e nos Estados Unidos, como royal agaricus, royal sun agaricus ou almond portobello.

O Brasil se destaca como o maior produtor mundial de A. blazei, por ser uma espécie nativa, apresentando as condições climáticas favoráveis para o seu cultivo.

\footnotetext{
'Extraído da Dissertação de Mestrado da primeira autora - Universidade Federal de Lavras/UFLA - Programa de Pós-graduação em Microbiologia Agrícola.

${ }^{2}$ Msc, Engenheira Agrônoma pela Universidade Federal de Lavras/UFLA - marcia tomizawa@yahoo.com.br

${ }^{3}$ Engenheiro Agrônomo, Dr. Professor do Departamento de Biologia da Universidade Federal de Lavras/UFLA - Cx. P. 3037 - $37200-000$ - Lavras, MG esdias@ufla.br

${ }^{4}$ Graduando em Ciências Biológicas na Universidade Federal de Lavras/UFLA, - Cx. P. 3037 - 37200-000 - Lavras, MG - leandro_lja@bol.com.br ${ }^{5}$ Graduando em Agronomia na Universidade Federal de Lavras/UFLA - Cx. P. 3037 - 37200-000 - Lavras, MG - Bolsista de Iniciação Científica PBIICT/FAPEMIG - phog c@hotmail.com

${ }^{6}$ Engenheiro Agrônomo, Dr. Professor do Departamento de Biologia da Universidade Federal de Lavras/UFLA - Cx. P. 3037 - $37200-000$ - Lavras, MG jbsantos@ufla.br
} 
A produção nacional atinge por ano 40 toneladas de cogumelo desidratado, sendo $95 \%$ da produção destinado à exportação para o mercado japonês. Devido ao seu elevado preço no mercado internacional muitas empresas $\mathrm{e}$ produtores rurais passaram a buscar nesse cogumelo, uma nova alternativa de renda. Várias empresas ou cooperativas têm comercializado o inóculo ("semente" ou spawn) de $A$. blazei ou o próprio composto colonizado. No entanto, pouco se sabe a respeito da origem e da variabilidade genética dos isolados utilizados para a produção comercial de inóculo.

Visto que alguns produtores enfrentam problemas no cultivo desse cogumelo, é de fundamental importância que, além dos aspectos tecnológicos de produção, haja um estudo para avaliar se os diferentes isolados utilizados atualmente no mercado apresentam um mesmo padrão genético, o que será importante para que o produtor tenha a segurança de que está adquirindo um material com inóculo de boa qualidade.

Além de permitir uma comparação entre os diferentes isolados, o uso de marcadores moleculares poderá ser importante futuramente para se fazer uma correlação entre os mesmos e alguns parâmetros importantes relacionados às propriedades farmacológicas dos cogumelos como atividade antitumoral, antimutagênica e bactericida.

Este trabalho teve como objetivo, analisar a variabilidade genética de isolados do cogumelo A. blazei, provenientes de diferentes regiões do País, por meio de marcadores RAPD.
Foram utilizados nove isolados de Agaricus blazei (CS1, CS2, CS3, CS4, CS5, CS6, CS7, CS8 e CS9) obtidos a partir de inoculantes ("sementes") de diferentes fontes comerciais, de cogumelos obtidos de produtores e também de cogumelos colhidos na região de origem no interior do Estado de São Paulo. Foram também utilizadas duas diferentes linhagens do cogumelo Agaricus bisporus ("Champignon de Paris" - CHP e "Portobello"-PB), que serviram como controle durante as análises moleculares. Todos estes isolados fazem parte da coleção de fungos do Laboratório de Cogumelos Comestíveis e Medicinais do Departamento de Biologia da UFLA e se encontram listados na Tabela 1.

Os isolados CS4, CS5 e CS7, correspondem, respectivamente, aos isolados ABL 97/11, ABL 99/25 e ABL 99/29 da coleção de cogumelos da UNESP/FCA de Botucatu, SP, os quais foram cedidos à coleção do Laboratório de Cogumelos Comestíveis e Medicinais do DBI/UFLA.

Para a manutenção das culturas e crescimento fúngico, os isolados foram cultivados em um meio de cultura denominado Meio Básico Completo (MBC), constituído de $1 \%$ de glicose, $0,1 \%$ de extrato de levedura, $0,1 \%$ de peptona, $0,1 \%$ de $\left(\mathrm{NH}_{4}\right)_{2} \mathrm{SO}_{4}, 0,1 \%$ de $\mathrm{KH}_{2} \mathrm{PO}_{4}$, $0,05 \%$ de $\mathrm{MgSO}_{4} .7 \mathrm{H}_{2} \mathrm{O}$ e $0,05 \%$ de $\mathrm{CaCl}_{2}, \mathrm{pH} 5,5$, o qual foi suplementado com micronutrientes $\left(\mathrm{FeSO}_{4} \cdot 7 \mathrm{H}_{2} \mathrm{O}-10 \mathrm{mg}\right.$, $\mathrm{MnCl}_{2} \cdot 4 \mathrm{H}_{2} \mathrm{O}-7 \mathrm{mg}, \mathrm{ZnSO}_{4} .7 \mathrm{H}_{2} \mathrm{O}-4 \mathrm{mg}, \mathrm{CuSO}_{4} \cdot 5 \mathrm{H}_{2} \mathrm{O}-$ $1 \mathrm{mg} / \mathrm{L}$ ). Para o cultivo em placas de petri, foi adicionado ágar a $1,5 \%$.

TABELA 1 - Relação dos isolados de Agaricus bisporus e A. blazei utilizados no estudo e sua procedência.

\begin{tabular}{lll}
\hline \multicolumn{1}{c}{ Espécie } & \multicolumn{1}{c}{ Isolado } & \multicolumn{1}{c}{ Procedência } \\
\hline Agaricus bisporus & CHP & São Paulo (Produtor) \\
Agaricus bisporus & PB & Estados Unidos \\
Agaricus blazei & CSI & Vitória, ES (Produtor) \\
Agaricus blazei & CS2 & Belo Horizonte, MG (Produtor) \\
Agaricus blazei & CS3 & Belo Horizonte, MG \\
Agaricus blazei & CS4 (ABL 97/11) & São Paulo, SP (Vitagaricus) \\
Agaricus blazei & CS5 (ABL 99/25) & Araçatuba, SP (Produtor) \\
Agaricus blazei & CS6 & Leme, SP \\
Agaricus blazei & CS7 (ABL99/29) & Porto Alegre, RS \\
Agaricus blazei & CS8 & Elói Mendes, MG (Produtor) \\
Agaricus blazei & CS9 & Elói Mendes, MG (Produtor) \\
\hline
\end{tabular}


A massa micelial utilizada para extração de DNA foi obtida em frascos de vidro contendo $150 \mathrm{~mL}$ do $\mathrm{MBC}$ líquido, os quais foram inoculados com fragmentos contendo micélio do fungo retirado das bordas de colônias crescidas em meio MBC sólido, com idade aproximada de 14 dias. Os frascos foram incubados à temperatura ambiente, sem agitação, por um período que variou de 25 a 30 dias de crescimento.

A extração de DNA total foi realizada com base na técnica descrita por Raeder \& Broda (1985). Após a extração, o DNA foi quantificado por meio do fluorímetro Hoefer Scientific TKO 100 e diluído com TE (Tris-HCl 1mM pH 8,0; EDTA 0,1mM) para concentração final de $10 \mathrm{ng} / \mu \mathrm{L}$, a qual foi usada nas reações de RAPD.

As reações de amplificação foram realizadas em um volume final de $12 \mu \mathrm{L}$, contendo 20 ng de DNA genômico, $0,4 \mu \mathrm{M}$ de primer, $100 \mu \mathrm{M}$ de cada dNTP (dATP, dTTP, dGTP, dCTP), tampão de reação pH 8,0 (50mM de Tris-HCl, 20mM de $\mathrm{KCl}, 2 \mathrm{mM}$ de $\mathrm{MgCl}_{2}, 250 \mu \mathrm{g} / \mathrm{mL}$ de BSA, $1 \%$ de ficoll $400,1 \mathrm{mM}$ de tartrazine), uma unidade da enzima Taq DNA polimerase e água Milli-Q autoclavada até o volume de $12 \mu \mathrm{L}$. As amplificações foram feitas em termociclador Mastercycler PCR (Eppendorf), programado para realizar uma desnaturação inicial a $94^{\circ} \mathrm{C}$ por 2 minutos, seguidos de 40 ciclos, sendo que cada ciclo consistiu de uma etapa de desnaturação a $94^{\circ} \mathrm{C}$ por 15 segundos, uma etapa de anelamento a $35^{\circ} \mathrm{C}$ por 30 segundos e uma etapa de extensão a $72^{\circ} \mathrm{C}$ por 1 minuto, e finalmente um extensão final a $72^{\circ} \mathrm{C}$ por 7 minutos.

Foram testados 108 primers, de diferentes seqüências aleatórias, sintetizadas pela empresa Operon Technologies. Pela Tabela 2, mostra-se os 50 primers e suas respectivas sequiências que apresentaram amplificação e polimorfismo de DNA e que foram utilizadas para análise de RAPD.

Os produtos amplificados foram separados por eletroforese em gel de agarose $1 \%$ imerso em tampão TBE (Tris-borato $0,045 \mathrm{M}$ e EDTA $0,001 \mathrm{M}$ ) a $80 \mathrm{~V}$, por aproximadamente 3 horas. Após o término da corrida de eletroforese, os fragmentos de DNA amplificados foram corados com brometo de etídio $(0,5 \mu \mathrm{g} / \mathrm{mL})$ e fotodocumentado sob luz ultravioleta.

Os dados obtidos nos géis de eletroforese foram transformados em dados binários (1 para presença e 0 para a ausência de bandas). Para análise, foram consideradas apenas as bandas fortes. Os dados foram analisados no programa NTSYS-PC 2.1, o qual construiu uma matriz de similaridade, utilizando o coeficiente de Dice (ROHLF, 1992). A partir dessa matriz foi construído o dendrograma pelo método de agrupamento UPGMA, estabelecendo as relações de similaridade genética entre os isolados.
TABELA 2 - Sequência e conteúdo de CG dos primers utilizados para análise de isolados de Agaricus spp. por marcadores RAPD.

\begin{tabular}{|c|c|c|}
\hline Primer & Sequência 5'- 3' & Conteúdo CG (\%) \\
\hline OPB-07 & GGTGACGCAG & 70 \\
\hline OPL-02 & TGGGCGTCAA & 60 \\
\hline OPL-06 & GAGGGAAGAG & 60 \\
\hline OPL-08 & AGCAGGTGGA & 60 \\
\hline OPL-10 & TGGGAGATGG & 60 \\
\hline OPL-14 & GTGACAGGCT & 60 \\
\hline OPL-15 & AAGAGAGGGG & 60 \\
\hline OPL-16 & AGGTTGCAGG & 60 \\
\hline OPL-18 & ACCACCCACC & 70 \\
\hline OPM-07 & CCGTGACTCA & 60 \\
\hline OPM-08 & TCTGTTCCCC & 60 \\
\hline OPM-09 & GTCTTGCGGA & 60 \\
\hline OPM-10 & TCTGGCGCAC & 70 \\
\hline OPM-11 & GTCCACTGTG & 60 \\
\hline OPM-13 & GGTGGTCAAG & 60 \\
\hline OPM-14 & AGGGTCGTTC & 60 \\
\hline OPM-15 & GACCTACCAC & 60 \\
\hline OPM-16 & GTAACCAGCC & 60 \\
\hline OPM-19 & CCTTCAGGCA & 60 \\
\hline OPM-20 & AGGTCTTGGG & 60 \\
\hline OPAN-01 & ACTCCACGTC & 60 \\
\hline OPAN-06 & GGGAACCCGT & 70 \\
\hline OPAN-12 & AACGGCGGTC & 70 \\
\hline OPAN-13 & CTTCCAGGAC & 60 \\
\hline OPAN-14 & AGCCGGGTAA & 60 \\
\hline OPAN-15 & TGATGCCGCT & 60 \\
\hline OPAN-17 & TCAGCACAGG & 60 \\
\hline OPAN-18 & TGTCCTGCGT & 60 \\
\hline OPAQ-06 & ACGGATCCCC & 70 \\
\hline OPAQ-08 & TCGGTAGACC & 60 \\
\hline OPAQ-10 & САТАСССТСС & 60 \\
\hline OPAQ-12 & CAGCTCCTGT & 60 \\
\hline OPAQ-14 & CCCGTGTAGG & 70 \\
\hline OPAT-20 & ACATCAGCCC & 60 \\
\hline OPAU-14 & CACCTCGACC & 70 \\
\hline OPAU-15 & TGCTGACGAC & 60 \\
\hline OPAU-17 & TTGGCATCCC & 60 \\
\hline OPAW-04 & AGGAGCGACA & 60 \\
\hline OPAW-08 & CTGTCTGTGG & 60 \\
\hline OPAW-10 & GGTGTTTGCC & 60 \\
\hline OPAW-12 & GAGCAAGGCA & 60 \\
\hline OPAW-14 & GGTTCTGCTC & 60 \\
\hline OPAW-16 & TTACCCCGCT & 60 \\
\hline OPAW-18 & GGCGCAACTG & 70 \\
\hline OPAX-18 & GTGTGCAGTG & 60 \\
\hline OPAX-20 & ACACTCGGCA & 60 \\
\hline OPAZ-04 & CCAGCCTCAG & 70 \\
\hline OPAZ-12 & GATGGGCCTG & 70 \\
\hline OPAZ-16 & AGGCGAACTG & 60 \\
\hline OPAZ-18 & CCGACGTTGA & 60 \\
\hline
\end{tabular}


Dos 108 primers testados no presente trabalho, 50 foram selecionados para análise de RAPD (Tabela 2). Estes primers foram selecionados de acordo com a amplificação dos fragmentos de DNA em todos os isolados e por apresentarem bandas polimórficas níticas, facilmente detectadas a olho nu, uma vez que, somente as bandas fortes foram consideradas para análise. Estes primers geraram um total de 445 bandas polimórficas, entre os isolados das duas espécies analisadas (A. bisporus e $A$. blazei). Considerando-se apenas os isolados de A. blazei, foram encontradas, no total, 139 bandas polimórficas em 46 primers analisados, obtendo-se uma média de três bandas polimórficas por primer. Na Figura 1, observa-se o padrão de bandas obtido com o primer OPAU-17, para os dois isolados de $A$. bisporus, e os nove isolados de $A$. blazei, revelando o polimorfismo entre as duas espécies do gênero Agaricus e do isolado CS2 em relação aos demais isolados de $A$. blazei analisados.

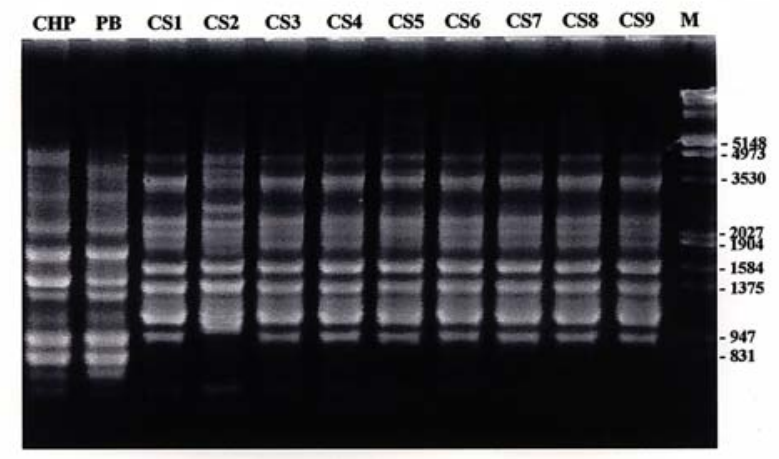

FIGURA 1 -Eletroforese em gel de agarose 1\% mostrando padrões de RAPD obtidos com os 2 isolados de Agaricus bisporus (controle) e os 9 isolados de Agaricus blaze $\mathrm{i}$ utilizando o primer OPAU-17. M - Marcador de peso molecular (pb) - DNA $\lambda /$ HindIII e EcoRI.

Os padrões de RAPD revelaram o polimorfismo existente entre as duas diferentes espécies de cogumelos analisadas, confirmando que espécies distintas apresentam padrões de bandas bem diferentes. Além disso, foi possível discriminar isolados dentro da mesma espécie, como o isolado CS2 de A. blazei, o qual apresentou-se distinto em praticamente todos os primers analisados, em relação aos demais isolados de $A$. blazei. Isto confirma a alta capacidade discriminatória da técnica de RAPD em estudos de diversidade genética de fungos, sendo uma técnica útil na diferenciação de isolados de várias espécies de cogumelos comerciais (CHIU et al., 1996; COLAUTO et al., 2002; KHUSH et al., 1992; RAMIREZ et al., 2001; ZHANG \& MOLINA, 1995).

O isolado CS5, também apresentou divergência em relação aos demais isolados estudados. No entanto, somente os primers: OPL-10, OPM-11, OPAN-18, OPAW04, OPAW-16, OPAZ-04, OPAZ-12, OPAZ-16, OPAZ-18, OPAQ-06, OPAQ-10 e OPAT-20 é que foram capazes de discriminá-lo em relação aos demais. Isto também foi observado para o isolado CS7, no qual foi possível detectar polimorfismo com os primers: OPB-07, OPM-09, OPAQ-06, OPAQ-10, OPAT-20, OPAW-04 e OPAZ-16. Na Figura 2 são mostrados os padrões de RAPD obtidos utilizando o primer OPAQ-06, indicando o polimorfismo dos isolados CS2, CS5 e CS7 em relação aos demais isolados de A. blazei.

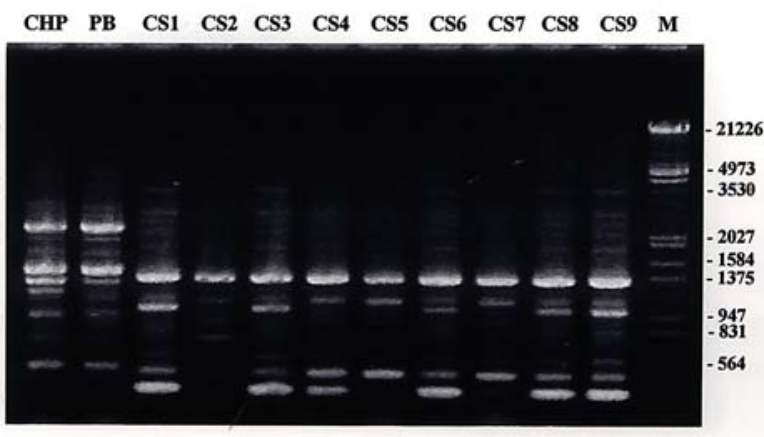

FIGURA 2 - Eletroforese em gel de agarose 1\% mostrando padrões de RAPD obtido com os isolados de Agaricus bisporus e Agaricus blazei, utilizando o primer OPAQ06. M - Marcador de peso molecular (pb) - DNA $\lambda /$ HindIII e EcoRI.

No isolado CS2 foram encontradas, no total, 53 bandas polimórficas, a partir de 34 primers, representando $38 \%$ do total de bandas polimórficas encontradas em todos os isolados de A. blazei. Estas bandas poderão futuramente ser isoladas e utilizadas como sondas ou para construção de primers específicos da espécie, facilitando desta forma, todo o processo de detecção e identificação da mesma. Assim como o CS2, o isolado CS5, também apresentou diferenças em relação aos demais isolados. Pela Figura 3, mostram-se os padrões de RAPD obtidos, utilizando o primer OPAW-16, no qual se verifica o polimorfismo nítido dos isolados CS2 e CS5 em relação aos demais isolados de A. blazei. 


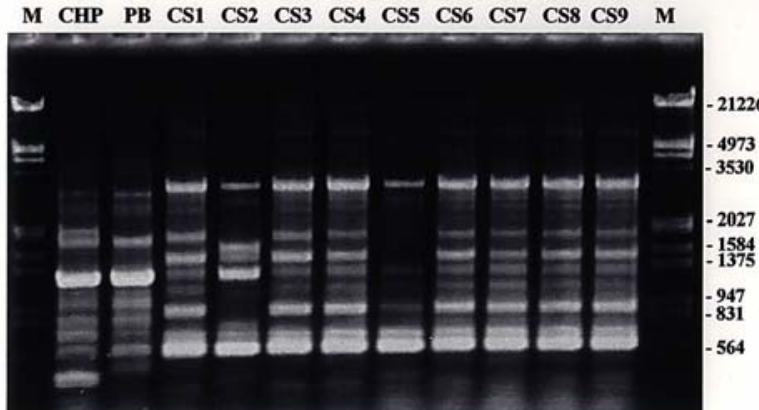

FIGURA 3 - Eletroforese em gel de agarose $1 \%$ mostrando padrões de RAPD obtido com os isolados de Agaricus bisporus e Agaricus blazei, utilizando o primer OPAW16. M - Marcador de peso molecular (pb) - DNA $\lambda /$ HindIII e EcoRI.

A análise combinada das 445 bandas polimórficas encontradas nos 11 isolados estudados (A. bisporus e $A$. blazei), permitiu a construção de um dendrograma pelo método de agrupamento UPGMA, baseado no coeficiente de Dice, que mostrou as relações de similaridade genética entre os isolados estudados (Figura 4). Na Tabela 3 mostra-se a matriz de similaridade genética (\%) entre os isolados de A. bisporus e A. blazei, construída com base nos padrões de RAPD.
Verifica-se na Figura 4, a formação de 2 grupos distintos, o primeiro agrupando os isolados de A. bisporus, e o segundo agrupando os isolados de A. blazei, o que já era esperado, uma vez que são de espécies distintas, apresentando um baixo grau de similaridade genética (média de 3\%). O grupo formado pelos isolados de A. blazei (Figura 4), também permitiu o agrupamento diferenciado entre os mesmos, indicando possíveis divergências genéticas entre eles. Adotando uma linha arbitrária a $98 \%$ de similaridade, foi observada a formação de 4 grupos distintos. O primeiro grupo foi formado pelos isolados CS1, CS3, CS4, CS6, CS8 e CS9, os quais apresentaram similaridade genética superior a $98 \%$, sendo que os pares de isolados CS1 e CS3, CS6 e CS9, apresentaram 100\% de similaridade, sendo, portanto, geneticamente idênticos, apesar de serem procedentes de locais diferentes do País (Tabela 1).

Os isolados CS7 (Porto Alegre, RS), CS5 (Araçatuba, $\mathrm{SP}$ ) e CS2 (Belo Horizonte, MG) formaram grupos distintos, apresentando níveis de similaridade genética abaixo de $96 \%$, com médias de $91,3 \%, 88,7 \%$ e $60,6 \%$, respectivamente. De todos eles, o isolado CS2 foi o que apresentou a maior divergência genética, em relação aos demais, apresentando similaridade variando de 59\% (CS1 e CS3) a 65\% (CS5) (Tabela 4). Portanto, não se observou uma correlação entre similaridade genética e origem dos isolados, uma vez que, a maior distância genética (ou menor similaridade genética)

TABELA 3 - Matriz de Similaridade Genética (\%) entre os isolados de A. bisporus e A. blazei, analisados dois a dois, de acordo com os padrões de RAPD e baseada no coeficiente de Dice.

\begin{tabular}{clllllllllll}
\hline \% & CHP & PB & CS1 & CS2 & CS3 & CS4 & CS5 & CS6 & CS7 & CS8 & CS9 \\
\hline CHP & 100 & & & & & & & & & & \\
PB & 78 & 100 & & & & & & & & & \\
CS1 & 3,8 & 3,3 & 100 & & & & & & & & \\
CS2 & 2,3 & 1,8 & 59 & 100 & & & & & & & \\
CS3 & 3,8 & 3,3 & 100 & 59 & 100 & & & & & & \\
CS4 & 3,8 & 3,3 & 99 & 60 & 99 & 100 & & & & & \\
CS5 & 3,4 & 2,3 & 92 & 65 & 92 & 92 & 100 & & & & \\
CS6 & 3,8 & 3,3 & 99 & 60 & 99 & 99 & 92 & 100 & & & \\
CS7 & 3,8 & 3,4 & 96 & 62 & 96 & 96 & 94 & 96 & 100 & & \\
CS8 & 3,7 & 3,3 & 98 & 60 & 98 & 98 & 91 & 98 & 95 & 100 & \\
CS9 & 3,8 & 3,3 & 99 & 60 & 99 & 99 & 92 & 100 & 96 & 98 & 100 \\
\hline
\end{tabular}

Ciênc. agrotec., Lavras, v. 31, n. 4, p. 1242-1249, jul./ago., 2007 


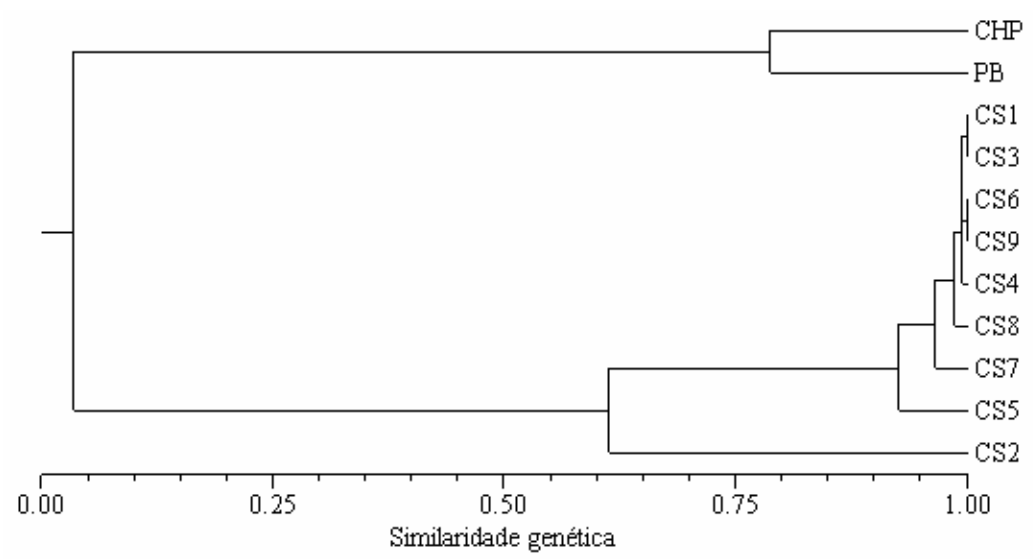

FIGURA 4 - Dendrograma de similaridade genética entre os isolados de Agaricus bisporus e A. blazei, de acordo com os padrões de RAPD, construído pelo método de agrupamento UPGMA, baseado no coeficiente de Dice.

foi observada entre isolados de mesma procedência (CS2 e CS3, ambos de $\mathrm{BH})$, como também procedentes de locais diferentes do País (CS2 e CS1, procedentes de BH e Vitória, ES, respectivamente). Observa-se também que, isolados obtidos de diferentes regiões do País (CS1, CS3, CS6, CS9, CS4 e CS8), apresentaram uma alta similaridade genética, suportando a idéia de que eles poderiam ter uma origem ou um ancestral em comum. Em vários outros trabalhos utilizando a técnica de RAPD, em diferentes fungos, também não foi possível estabelecer uma relação entre a similaridade genotípica e/ou polimorfismo encontrado, e a origem geográfica dos isolados (FRAZZON et al., 2002; TEIXEIRA et al., 2004; TIGANO et al., 2003).

Colauto et al. (2002), caracterizando 5 isolados do cogumelo A. blazei também por análise de RAPD, verificaram que 3 deles (ABL 97/11, ABL 99/25, ABL 99/29) não apresentaram qualquer divergência, sendo caracterizados como isolados de uma mesma origem, apesar de terem sido obtidos de locais diferentes do País. Os resultados encontrados por Colauto et al. (2002), no entanto, contradizem com os resultados obtidos neste trabalho, uma vez que foi encontrada uma divergência genética de 6\% entre os isolados CS5 (ABL 99/25) e CS7 (ABL 99/29) e isto pode ser justificado, uma vez que um pequeno número de primers ( 8 primers) e isolados foram utilizados por estes autores, não encontrando nenhuma divergência genética entre eles. Contudo, os mesmos autores recomendaram que estudos adicionais deveriam ainda, ser realizados utilizando um maior número de primers e também novos isolados, com o intuito se avaliar melhor a variabilidade genética da espécie $A$. blazei. Portanto, no presente estudo, utilizando um maior número de primers, detectou-se algumas diferenças entre os isolados CS5 e CS7 de A. blazei, os quais apresentaram uma similaridade genética de $94 \%$.

Os resultados obtidos neste trabalho indicam que alguns isolados vendidos como inoculantes, pelas diferentes empresas (CS1, CS3, CS4, CS6, CS8 e CS9), apresentam características genotípicas muito próximas, sendo provavelmente clones, apresentando uma origem em comum. Acredita-se que a grande maioria dos isolados utilizados comercialmente seja originária da região de $\mathrm{P}$ iedade, SP, de onde se espalharam para vários outros locais do País. N o entanto, ressalta-se ainda, que os isolados analisados no presente estudo, m esm o tendo sido coletados em regiões diferentes do País, não foram obtidos na natureza, $m$ as sim de cultivos com erciais, podendo alguns deles, terem sido fomecidos por um a m esm a em presa, apresentando desta form a, um a elevada sim ilaridade genética.

O s resultados obtidos m ostraram que os isolados CS7, CS5 e princịpalm ente o CS2, são geneticam ente divergentes em relação aos dem ais, e isto provavelm ente pode ter sido ocasionado pelo processo de recom binação genética ou m utação, que são as fontes de variabilidade genética que podem ocorrer naturalm ente entre os organism os vivos (COLAUTO et al., 2002; RAMIREZ et al., 2001).

Labory (2003), em estudos sobre os aspectos citológicos e condições de crescimento do A. blazei, verificou que o isolado CS2 apresentou o menor número de núcleos por célula (média de 5,34) e também as menores dimensões celulares, como comprimento $(49,20 \mu \mathrm{m})$, largura $(4,38 \mu \mathrm{m})$ e menor área celular 
$\left(215,50 \mu_{m^{2}}\right)$, em relação aos demais isolados. Em relação às condições de crescimento, de uma maneira geral, o isolado CS2 também foi um dos isolados que apresentou os menores desempenhos em relação ao crescimento micelial, o qual foi avaliado em diferentes meios de cultura, sob diferentes níveis de $\mathrm{pH}$.

O trabalho realizado por Gaspar Júnior (2003) sobre a caracterização enzimática de isolados de $A$. blazei, evidenciou uma diferença de atividade da celulase entre os isolados, sendo que CS2 e CS6 apresentaram os menores picos de atividade de exo e endoglucanase e para $\beta$-glicosidade, os mesmos isolados apresentaram a maior atividade em relação aos demais. Segundo o autor, esses resultados indicam que os isolados estudados poderiam ser separados em dois ou três grupos segundo a sua capacidade de utilização da celulose.

Estes resultados confirmam que o isolado CS2 é realmente distinto dos demais, tanto nos aspectos citológicos, fisiológicos e enzimáticos, provavelmente relacionados com as diferenças genéticas reveladas pela técnica de RAPD. Portanto, fica evidenciada a necessidade de maiores estudos com relação a este isolado, acerca das características agronômicas, tais como produtividade, cor e tamanho do cogumelo, bem como das suas propriedades medicinais, para verificar o seu potencial para ser utilizado futuramente em um programa de melhoramento genético da espécie.

\section{AGRADECIMENTOS}

À CAPES - Coordenadoria de Aperfeiçoamento de Pessoal de Nível Superior, pela concessão da bolsa de estudo e à FAPEMIG - Fundação de Amparo a Pesquisa de Minas Gerais, pelo financiamento do projeto.

\section{REFERÊNCIAS BIBLIOGRÁFICAS}

AMAZONAS, M. A. L. de A. Agaricus brasiliensis (= Agaricus blazei ss. Heinem.): última visão sobre a polêmica questão da identidade taxonômica de um dos cogumelos mais promissores no mercado mundial. In: SIMPÓSIO INTERNACIONAL SOBRE COGUMELOS NO BRASIL, 2., 2004, Brasília, DF. Anais... Brasília, DF: Embrapa, 2004. p. 78-80. (Documentos, 116).

CHIU, S. W.; MA, A. M.; LIN, F. C.; MOORE, D. Genetic homogeneity of cultivated strains of Shiitake (Lentinula edodes) used in China as revealed by the polymerase chain reaction. Mycological Research, Cambridge, v. 100, n. 11, p. 1393-1399, Nov. 1996.
COLAUTO, N. C.; DIAS, E. S.; GIMENES, M. A.; EIRA, A. A. Genetic characterization of isolates of the basidiomycete Agaricus blazei by RAPD. Brazilian Journal of Microbiology, São Paulo, v. 33, n. 2, p. 131133, Apr./June 2002.

FRAZZON, A. P. G.; MATSUMURA, A. T. S.; SAND, S. T. van der. Morphological characterization and genetic analysis of Drechslera teres isolates. Genetics and Molecular Biology, Ribeirão Preto, v. 25, n. 2, p. 235-241, June 2002.

GASPAR JÚNIOR, P. J. Requerimentos nutricionais e caracterização enzimática de isolados do cogumelo Agaricus blazei. 2003. 65 p. Dissertação (Mestrado em Ciência dos Alimentos) - Universidade Federal de Lavras, Lavras, 2003.

KHUSH, R. S.; BECKER, E.; WACH, M. DNA amplification polymorphisms of the cultivated mushroom Agaricus bisporus. Applied and Environmental Microbiology, Washington, v. 58, n. 9, p. 2971-2977, Sept. 1992.

LABORY, C. R. Avaliação citológica e condições de crescimento de Agaricus blazei. 2003. 60 p. Tese (Doutorado em Ciência dos Alimentos) - Universidade Federal de Lavras, Lavras, 2003.

MIZUNO, T. Kawariharatake, Agaricus blazei Murill: medicinal and dietary effects. Food Reviews International, Madison, v. 11, n. 1, p. 167-172, 1995.

RAEDER, U.; BRODA, P. Rapid preparation of DNA from filamentous fungi. Letters Applied Microbiology, Oxford, v. 1, n. 1, p. 17-20, Jan. 1985.

RAMIREZ, L.; MUEZ, V.; ALFONSO, M.; BARRENECHEA, A. G.; ALFONSO, L.; PISABARRO, A. G. Use of molecular markers to differentiate between comercial strains of the button mushroom Agaricus bisporus. FEMS Microbiology Letters, Amsterdam, v. 198, n. 1, p. 45-48, Apr. 2001.

ROHLF, F. J. Numerical taxonomy and multivariate analysis system. Version 1.70. New York: [s.n.], 1992. 470 p.

TEIXEIRA, H.; VIEIRA, M. D. G. G. C.; MACHADO, J. C. Marcadores RAPD na análise da diversidade genética de isolados de Acremonium strictum. Fitopatologia Brasileira, Brasília, v. 29, n. 6, p. 651-655, nov./dez. 2004. 
TIGANO, M. S.; ALJANABI, S.; MELLO, S. C. M. de. Genetic variability of brazilian Alternaria spp. isolates as revealed by RAPD analysis. Brazilian Journal of Microbiology, São Paulo, v. 34, n. 2, p. 117-119, Apr./June 2003.
ZHANG, Y.; MOLINA, F. I. Strain typing of Lentinula edodes by random amplified polymorphic DNA assay. FEMS Microbiology Letters, Amsterdam, v. 131, n. 1, p. 17-20, 1995. 